\title{
Investigation of the impact of geometry of the riser on the location and shape of shrinkage cavity
}

\author{
Tomasz Skrzypczak ${ }^{1, *}$, Ewa Wegrzyn-Skrzypczak ${ }^{2}$, and Leszek Sowa ${ }^{1}$ \\ ${ }^{1}$ Czestochowa University of Technology, Faculty of Mechanical Engineering and Computer Science, \\ Institute of Mechanics and Machine Design Fundamentals, Dąbrowskiego 73, 42-201 Częstochowa, \\ Poland \\ ${ }^{2}$ Czestochowa University of Technology, Faculty of Mechanical Engineering and Computer Science, \\ Institute of Mathematics, Armii Krajowej 21, 42-201 Częstochowa, Poland
}

\begin{abstract}
During solidification process the phenomenon of shrinkage cavity is often observed. It has negative impact on the structure and physical properties of the final product. To minimize the negative effect of shrinkage cavity the riser is commonly introduced to the solidifying system. If the riser is properly designed shrinkage cavity rather appears within its volume than in the other parts of the casting. It makes possible to obtain defect-free main part of the casting. Presented work shows the impact of the different shapes of the riser on the localization of the shrinkage cavity. The results are obtained with the use of an original computer program based on the finite element method (FEM). They are presented for three-dimensional case of solidification of three types of the riser. The comparison of the results is discussed in details.
\end{abstract}

Keywords: solidification, riser, shrinkage cavity, finite element method, numerical modelling

\section{Introduction}

Riser plays an important role in the process of metal casting since casting defects are the most important issues occurring in the process [1-3]. It is a reservoir of liquid metal, which complements the volume loss of material appearing in the process of cooling above liquidus temperature $T_{L}[\mathrm{~K}]$ and also during solidification process. The amount of liquid contraction due to temperature is governed by the coefficient of volume expansion $a\left[\mathrm{~K}^{-1}\right]$. The difference between the volume of liquid and the solid formed upon solidification depends on the phase change contraction coefficient of the material $S_{h}[-]$. The riser is usually placed at the top of the casting because the supply of liquid to the system is governed by the force of gravity. Before the stage of solid phase growth the level of liquid metal in the riser decreases according to the difference between initial temperature $T_{0}[\mathrm{~K}]$ and $T_{L}$. The loss of

\footnotetext{
* Corresponding author: t.skrzypczak@imipkm.pcz.pl

Reviewers: Michat Śledziński, Radim Halama
} 
volume during solidification is of great importance because it causes the shrinkage cavity formation. Shape of the riser and cooling conditions play important role in this process. Molten metal inside the riser should solidify at the end of the process providing the supply of liquid during entire process. It can be obtained if the top of the riser has good thermal insulation $[4,5]$. Numerical modelling of the solidification with shrinkage cavity formation and computer simulations of this process is the area of interests of many scientists [6-8]. Many computer simulation programs such AutoCAST, MAGMASOFT SolidCAST, ProCAST are available to predict shrinkage cavities. The review of possible simulations of casting defects with the use of dedicated programs is presented in [9].

\section{Mathematical and numerical models}

Mathematical description of the problem as well as the basis of numerical model including shrinkage cavity formation are presented in [10]. Presented paper contains only the most important aspects of these models. The following partial differential equation describes the problem:

$$
\nabla \cdot(\lambda \nabla T)-C \rho \frac{\partial T}{\partial t}=0
$$

where $T[\mathrm{~K}]$ is the temperature, $t[\mathrm{~s}]$ denotes time, $\lambda\left[\mathrm{J}^{-1} \mathrm{~s}^{-1} \cdot \mathrm{m}^{-1} \cdot \mathrm{K}^{-1}\right]$ is the thermal conductivity coefficient, $\rho\left[\mathrm{kg} \mathrm{m}^{-3}\right]$ represents density, $C\left[\mathrm{~J} \mathrm{~kg}^{-1} \mathrm{~K}^{-1}\right]$ is the effective specific heat which includes the latent heat of solidification.

Equation (1) is complemented by the following conditions:

$$
\begin{array}{cc}
t=0: & T(x, y, z, t)=T_{0} \\
(x, y, z) \in \Gamma_{e x t}: & -\mathbf{n} \cdot \lambda \nabla T=\alpha\left(T-T_{\infty}\right), \\
(x, y, z) \in \Gamma_{s y m}: & -\mathbf{n} \cdot \lambda \nabla T=0
\end{array}
$$

where $x, y, z[\mathrm{~m}]$ denote the spatial coordinates, $\mathbf{n}$ is the unit vector perpendicular to the external boundary $\Gamma_{\text {ext }}, \alpha\left[\mathrm{J} \cdot \mathrm{s}^{-1} \cdot \mathrm{m}^{-2} \cdot \mathrm{K}^{-1}\right]$ represents the heat transfer coefficient, $T_{\infty}[\mathrm{K}]$ is the ambient temperature.

Numerical model uses the Finite Element Method (FEM). Solidifying volume $\Omega$ is spatially discreticed to obtain the set of simple geometric primitives called "finite elements". In this case four-node tetrahedrons are chosen. In the next step the standard Galerkin formulation is used to formulate local equation for each tetrahedron. Finally backward Euler method is used in the procedure of time discretization which leads to global FEM equation in the following form:

$$
\left(\mathbf{K}+\frac{1}{\Delta t} \mathbf{M}\right) \mathbf{T}^{f+1}=\frac{1}{\Delta t} \mathbf{M T}^{f}+\mathbf{B}
$$

where $\mathbf{M}$ is the heat capacity matrix, $\mathbf{K}$ represents the thermal conductivity matrix while $\mathbf{B}$ is the vector containing boundary conditions, $f$ is related to the time level, $\Delta t[\mathrm{~s}]$ represents the value of time step.

\section{Pre-processing of the problem data}

Three tasks of numerical calculations were performed to compare the impact of the shape of riser on the structure and localization of shrinkage cavity. At the beginning finite element 
meshes were prepared with the use of free three-dimensional mesh generator GMSH. It has also post-processing capabilities which were used to visualize obtained results of calculations. Fig. 1a-c shows three shapes of the riser which were used in numerical calculations of shrinkage cavity formation process.
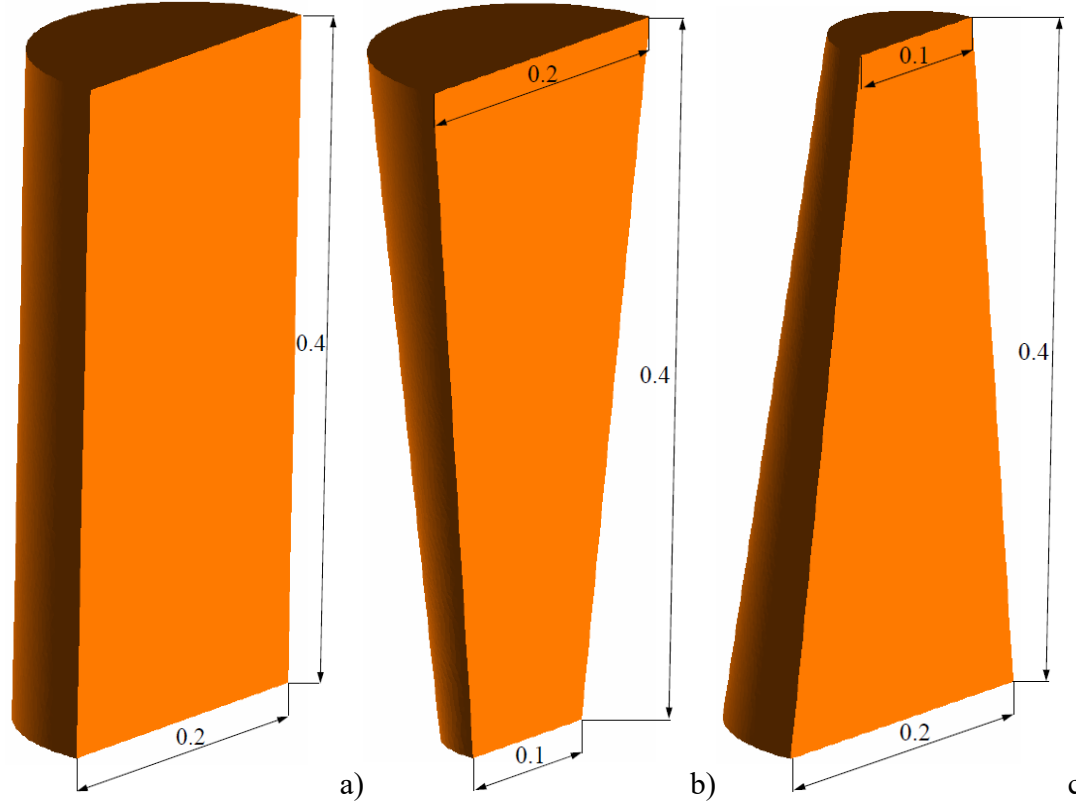

c)

Fig. 1. Shapes of the riser used in calculations (dimensions in meters)

Only a half of the riser was taken into account due to symmetry. The plane of symmetry and the bottom surface were thermally insulated. Bottom surface lies between the riser and the rest of the casting which was omitted in the geometry creation process.

In the process of pre-processing the continuous volume of the riser was meshed with the use of tetrahedral finite elements (Fig. 2a-c). The most important mesh parameters are presented in Table 1.

Table 1. Mesh parameters for three cases of the riser geometry

\begin{tabular}{|c|c|c|c|}
\hline \multirow{2}{*}{ Riser } & \multirow{2}{*}{$\begin{array}{c}\text { Element size } \\
{[\mathbf{m m}]}\end{array}$} & $\begin{array}{c}\text { Number of } \\
\text { tetrahedrons }\end{array}$ & $\begin{array}{c}\text { Number of } \\
\text { nodes }\end{array}$ \\
\cline { 1 - 3 } (a) & & 279336 & 55909 \\
\hline (b) & \multirow{3}{*}{\begin{tabular}{c}
3.75 (top) \\
\cline { 3 - 4 }
\end{tabular} (bottom) } & 176975 & 36593 \\
\cline { 1 - 1 } (c) & & 149480 & 31413 \\
\hline
\end{tabular}

The mesh at the top of the riser is slightly finer than at the bottom for better simulation of the shrinkage cavity formation. The size of finite elements increases smoothly from 3.75 $\mathrm{mm}$ at the top surface to $5 \mathrm{~mm}$ at the bottom.

Heat transfer through the riser external boundaries was governed by the Newton boundary conditions (3) with $\alpha=200 \mathrm{~J} \cdot \mathrm{s}^{-1} \cdot \mathrm{m}^{-2} \cdot \mathrm{K}^{-1}$ at the side surface and $\alpha=20 \mathrm{~J} \cdot \mathrm{s}^{-1} \cdot \mathrm{m}^{-2} \cdot \mathrm{K}^{-1}$ at the top surface. Ambient temperature $T_{\infty}$ was $300 \mathrm{~K}$. Initial temperature of the liquid metal $T_{0}$ was $1800 \mathrm{~K}$. Calculations were performed with constant time step $\Delta t=0.05 \mathrm{~s}$. Material properties of the liquid and solid fractions as well as the air filling shrinkage cavity are stored in Table 2. 

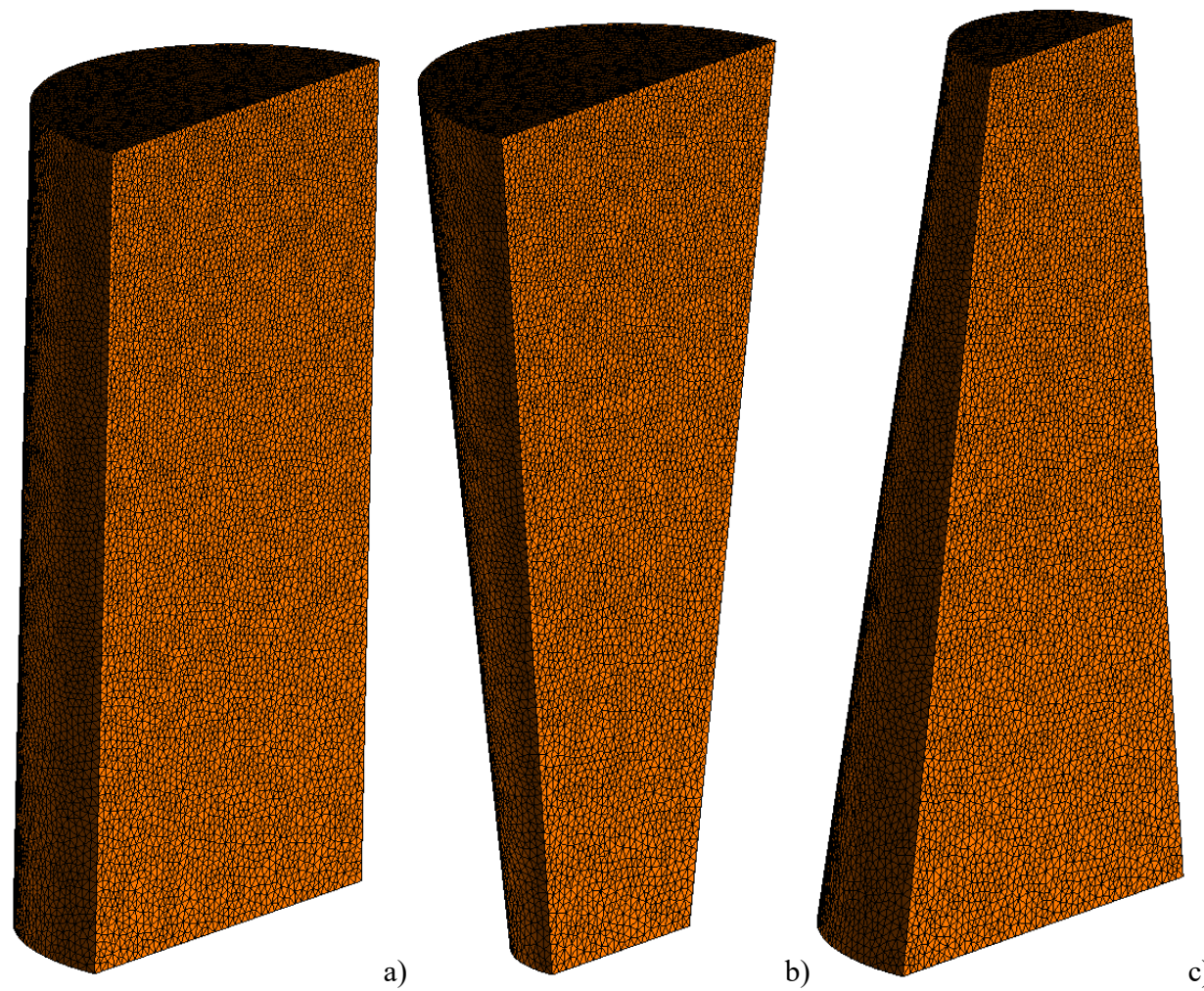

Fig. 2. Finite element meshes generated with the use of GMSH

Table 2. Material properties used in calculations

\begin{tabular}{|c|c|c|c|}
\hline Material property & Liquid & Solid & $\begin{array}{c}\text { Air } \\
\left(T=1500^{\circ} \mathrm{C}\right)\end{array}$ \\
\hline$\lambda\left[\mathrm{J} \cdot \mathrm{s}^{-1} \cdot \mathrm{m}^{-1} \cdot \mathrm{K}^{-1}\right]$ & 23 & 35 & 0.096 \\
\hline$\rho\left[\mathrm{kg} \cdot \mathrm{m}^{-3}\right]$ & 6915 & 7800 & 0.2 \\
\hline$c\left[\mathrm{~J} \cdot \mathrm{kg}^{-1} \cdot \mathrm{K}^{-1}\right]$ & 837 & 644 & 1234 \\
\hline$T_{L}[\mathrm{~K}]$ & \multicolumn{2}{|c|}{1766} & \\
\hline$T_{S}[\mathrm{~K}]$ & \multicolumn{2}{|c|}{1701} & \\
\hline$L\left[\mathrm{~J} \cdot \mathrm{kg}^{-1}\right]$ & \multicolumn{2}{|c|}{270000} & \\
\hline$S_{h}[-]$ & \multicolumn{3}{|c|}{0.04} \\
\hline
\end{tabular}

\section{Discussion of the results}

Results of the numerical calculations are shown in Figs. 3-5. Temperature distribution and shrinkage cavity development in the risers are presented for the chosen moments. 


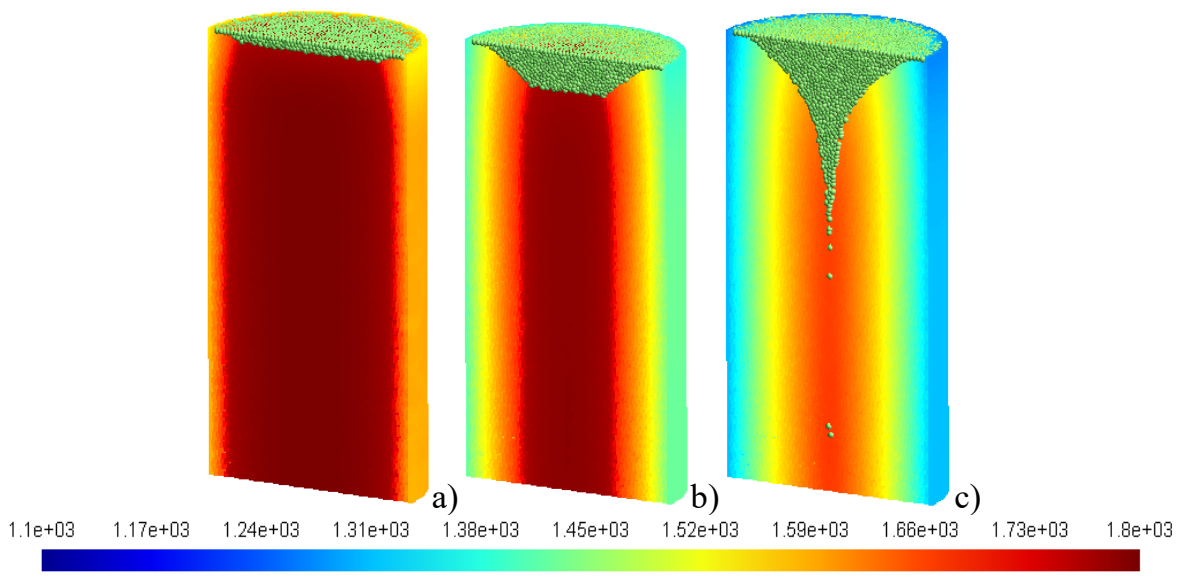

Fig. 3. Temperature distribution and shrinkage cavity formation in the first riser a) $150 \mathrm{~s}$, b) $300 \mathrm{~s}$, c) $460 \mathrm{~s}$
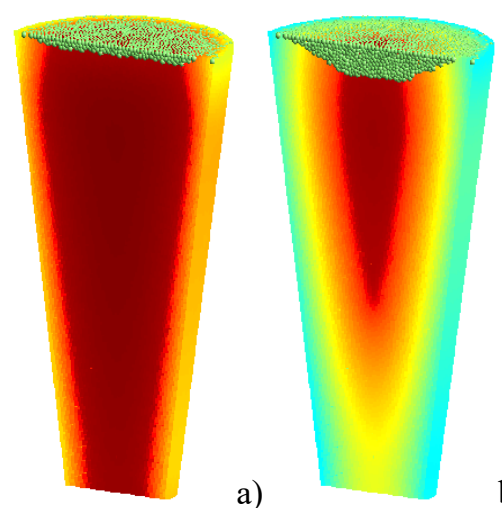

b)

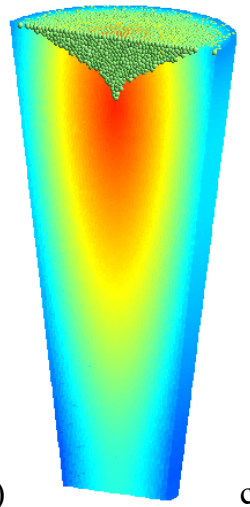

$1.1 \mathrm{e}+03 \quad 1.17 \mathrm{e}+03 \quad 1.24 \mathrm{e}+03 \quad 1.31 \mathrm{e}+03$

$1.38 \mathrm{e}+03 \quad 1.45 \mathrm{e}+0.3$

$152 \mathrm{e}+03 \quad 1.59 \mathrm{e}+03-1.60 \mathrm{e}+03$

c)

Fig. 4. Temperature distribution and shrinkage cavity formation in the second riser a) $150 \mathrm{~s}$, b) $300 \mathrm{~s}$, c) $390 \mathrm{~s}$

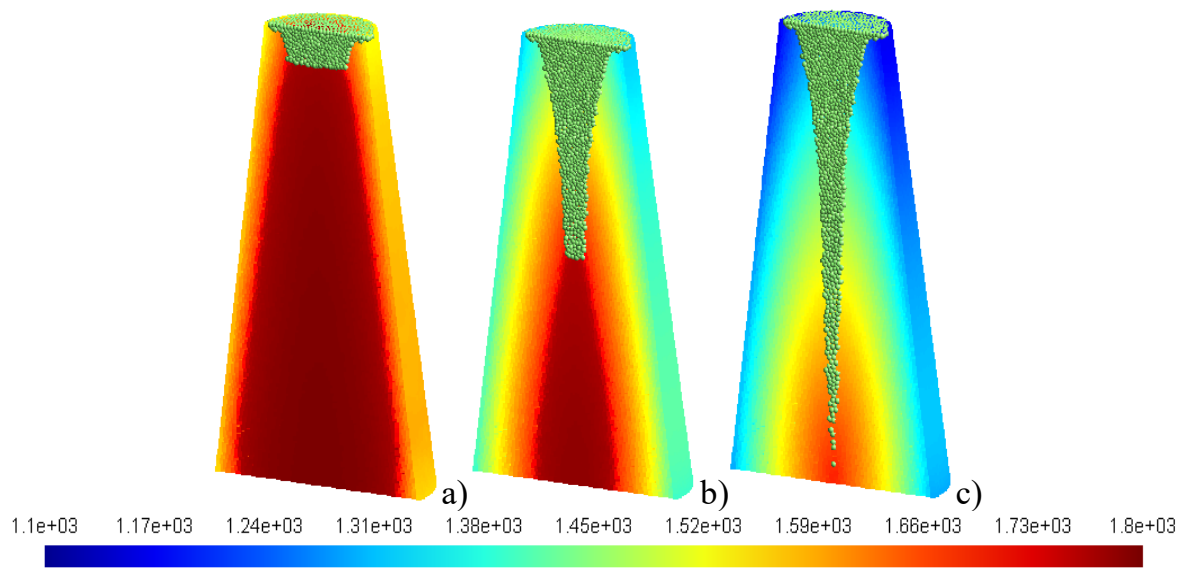

Fig. 5. Temperature distribution and shrinkage cavity formation in the third riser a) $150 \mathrm{~s}, \mathrm{~b}) 300 \mathrm{~s}, \mathrm{c}$ ) $425 \mathrm{~s}$ 
The shape and localization of the shrinkage cavity depends on the position of the thermal centre in the riser. This is the hottest spot in the considered volume which moves up or down according to the shape of the riser and also the cooling conditions. The best riser is shown in Fig. 4 because the thermal centre moves upward providing smallest vertical size of the defect which is localized in the upper part of the volume. The worst shape of the riser is presented in Fig. 5 due to very deep shrinkage cavity. Thermal centre moves downwards in this case and it is possible that presented defect will appear below the riser in the main part of the casting. Cylindrical riser (Fig. 3) is also not the best choice. The hottest area lies along the vertical central axis of the riser allowing the formation of the shrinkage cavity from the bottom to the top.

\section{Conclusions}

Presented results of the numerical calculations shows the possible application of the original computer program based on the FEM and made with the use of Visual C++ environment. It is very important to design the riser in the proper way to provide the highest possible probability of obtaining defect-free final product. It could be easily done with the use of presented application which is usable in the case of complex $3 \mathrm{D}$ geometries and different cooling conditions.

\section{References}

1. Casting design handbook: prepared from the contributions of 18 committees. (American Society for Metals: Metals Park, OH, United States, 1962)

2. Metals handbook. Forging and casting. (American Society for Metals: Metals Park, OH, United States, 1970)

3. R. Dyja N. Sczygiol, Z. Domański, The formation of cavities in castings and their impact on the conditions of heat dissipation. Proceedings of the International Multi Conference of Engineers and Computer Scientists 2, 819-823 (2013)

4. C. K. Jin, H. Y. Seo, C. G. Kang, Heating system for riser size minimizing in sand casting process and its experimental verification., Metals 7(130), 12p (2017)

5. I. Vasková, M. Conev, M. Hrubovčáková, The influence of using different types of risers or chills on shrinkage production for different wall thickness for Material ENGJS-400-18LT., Arch. Foundry Eng. 2, 131-136 (2017)

6. L. Sowa, Numerical simulation of the shrinkage cavity within solidifying steel casting, Arch. Foundry, 2(4), 245-250 (2002)

7. S. Bockus, A. Venckunas, G. Zaldarys, Simulation of a shrinkage cavity in the risers of ductile iron castings, Mater. Sci., 11(1), 19-23 (2005)

8. L. Sowa, Mathematical model of solidification of the axisymmetric casting while taking into account its shrinkage., J. Appl. Math. Comput. Mech. 13(4), 123-130 (2014)

9. V. Vasava, D. Joshi, Simulation of shrinkage defect - A review., IJETT 4(6), 2361-2365 (2013)

10. T. Skrzypczak, E. Węgrzyn-Skrzypczak, L. Sowa, Numerical model of solidification process of $\mathrm{Fe}-\mathrm{C}$ alloy taking into account the phenomenon of shrinkage cavity formation. MATEC Web Conf. (to be published) 